\title{
PAINLESS INTRATHECAL HYPERTONIC SALINE
}

\author{
A.W. SQuire, M.B., ${ }^{*}$ O. Calvillo, M.D., aNd P.R. Bromage, M.D., B.S., F.F.A.R.C.S.
}

IN 1967 Hrтснсоск proposed intrathecal infusions of cold saline as a therapeutic method for relieving intractable pain. ${ }^{1}$ Hitchcock's technique for preparing cold saline ensured that the solution was also appreciably hypertonic, and further work led to the view that success depends upon the hypertonicity of the solution injected, rather than on its temperature ${ }^{2,3}$ Unfortunately, the presence of hypertonic saline in the delicate precincts of the subarachnoid space is an insult that produces some undesirable effects. First, severe pain and muscle cramps occur in the affected segments. ${ }^{4}$ Second, a brisk sympathetic response causes arterial hypertension ${ }^{5,6}$ and occasionally cardiac arrhythmias ${ }^{2}$ : even pulmonary oedema ${ }^{7}$ and cerebral infarction ${ }^{5}$ have been reported. Heavy sedation or general anaesthesia is commonly used to control these side effects during the period of intense stimulation, ${ }^{4,8}$ and Neilsen has used epidural analgesia to block sympathetic fibres. ${ }^{9}$

In this communication we show that simple and apparently safe control of the painful and potentially dangerous neural discharge can be achieved by using subarachnoid anaesthesia. We have observed the effects in man of intrathecal injections of limited volumes of strongly hypertonic saline, mixed with a weak concentration of a local anaesthetic agent. Serial measurements of cerebrospinal fluid osmolality were made to confirm that the technique produced a significant degree of hypertonicity.

Experiments in dogs involving intrathecal injections of hypertonic saline with and without local anaesthetic are in progress, in an attempt to elucidate the serial changes which occur in arterial and cerebrospinal fluid pressures.

\section{METHODS}

Twenty millilitre vials of eight per cent sodium chloride in distilled water with $4 \mathrm{mg}$ of lidocaine hydrochloride per millilitre, that is, 0.4 per cent, were prepared by the hospital pharmacy, and autoclaved prior to use. The calculated osmolality of the mixture was $2788 \mathrm{~m} . \mathrm{Osmols} / \mathrm{Kg}$, and the measured osmolality was 2700 $2900 \mathrm{~m}$. Osmols $/ \mathrm{Kg}$, that is, approximately ten times the osmolality of normal cerebrospinal fluid. The specific gravity was 1.050 at $20^{\circ} \mathrm{C}$.

Observations were made of 14 subarachnoid injections in 9 patients suffering from intractable pain of the trunk and lower extremities. Subarachnoid puncture was made at an appropriate interspace using a 22-gauge spinal needle. The level of injection and the position of the patient were chosen to favour distribution of the hypertonic solution to the affected segments.

Fifteen millilitres of cerebrospinal fluid were aspirated, and $15 \mathrm{ml}$ of the hypertonic mixture were injected at room temperature, with the patient sitting

Departments of Anaesthesia, Royal Victoria Hospital \& McGill University

-Present address: Memorial University, Newfoundland. 
or tilted head up. The spinal needle was left in place, and $2 \mathrm{ml}$ samples of cerebrospinal fluid were taken at 2, 5, 8, 10 and 15 minutes after injection. The samples were examined for osmolality and chloride content. Arterial blood pressure was measured by arm cuff. An intravenus infusion was started at the beginning of the procedure, and 1 litre of 5 per cent glucose in water was given over a two to three hour period. Patients were allowed to lie supine at about 20 minutes after completion of sampling and were permitted unlimited activity on the evening of injection.

\section{Results}

Injection of the hypertonic saline-local anaesthetic mixture was painless, and was not accompanied by muscle spasms or by elevation of blood pressure. No disturbances of pulse rate or rhythm were detected. Five of the nine patients received the injection on two occasions owing to incomplete therapeutic effects from the first, and they faced the second with no trace of fear or anxiety.

The upper level of skin analgesia in the 9 patients varied between the second lumbar and the second cervical segments. Respiration was not affected, and motor block in the lower limbs varied from minimal weakness to complete paralysis, lasting about one hour. None of the patients complained of headache at any stage. One, with skin anaIgesia to the second cervical dermatome, experienced transient subjective breathlessness occurring shortly after injection and lasting about two minutes, but had no evidence of motor block. A moderate fall in blood pressure occurred in one patient with a sensory level to T9 though he maintained the sitting position without treatment. Arterial hypotension did not occur on the three occasions in which the sensory level rose as high as the second cervical dermatome.

Changes of cerebrospinal fluid osmolality and chloride ion concentration are shown in Figure 1. It can be seen that the curves are very similar. The osmolality at the site of injection was increased four to eight-fold for a period of 5 minutes, and was still three to six times greater than normal 15 minutes after injection.

The analgesia and associated variable weakness of the lower limbs caused by the lidocaine began to wane at about $45-60$ minutes and had fully regressed by 90 minutes.

On six occasions, patients complained of aching pain in the lower back, buttocks and thighs, starting 50-90 minutes after injection, and severe enough to require morphine for relief. In 3 patients the blood pressure rose significantly at this point, as the effects of the local anaesthetic were beginning to wear off. In one patient with labile hypertension, whose arterial pressure before and during the procedure varied between 220 and $240 \mathrm{~mm} \mathrm{Hg}$, the systolic pressure rose to $280 \mathrm{~mm} \mathrm{Hg}$ and antihypertensive therapy was instituted, since no improvement occurred when delayed pain was relieved with morphine.

Therapeutic results varied from transient and partial relief in 8 patients to complete relief in one, until his death one month later. 

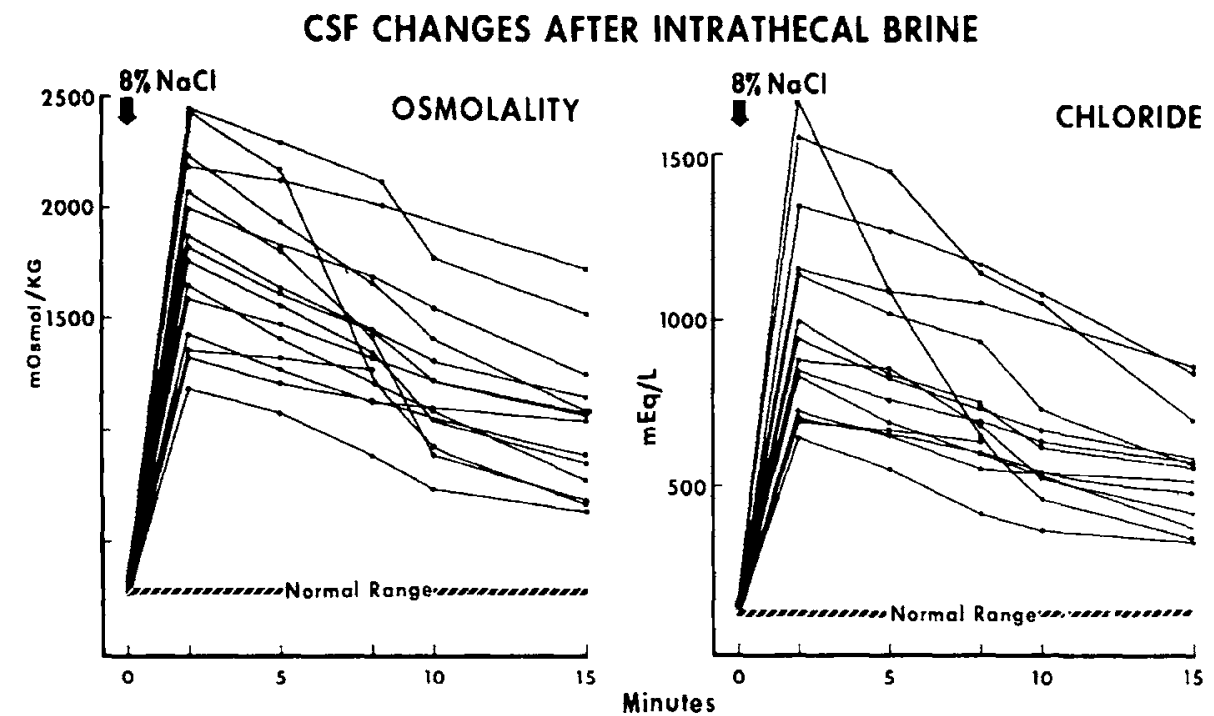

Figune 1. Serial measurements of cerebrospinal fluid osmolality and chloride content in man, after injection of $15 \mathrm{ml}$ of 8 per cent $\mathrm{NaCl}+0.4$ per cent lidocaine.

\section{Discussion}

Hypothermic blockade of nerve conduction is a transient phenomenon, and unless carried to the extreme of intracellular freezing, is incapable of producing permanent effects. Hitchcock's initial proposal that permanent analgesia could be produced by hypothermic irrigation was soon replaced by other explanations. Hypertonicity, ${ }^{2}$ or chloride ion imbalance ${ }^{10}$ were invoked as possible mechanisms, and it is still not clear which of the two is the more important, or indeed whether some other factor may not be involved. Relief of severe intractable pain has occurred following mere barbotage of the cerebrospinal fluid. ${ }^{11}$

At the present time the technique of intrathecal saline is disturbingly imprecise in both theory and practice, and the long term results and complications have not been evaluated. Nevertheless, with concentrations less than 10 per cent there is no positive evidence of significant neurological sequelae - hence the technique is acceptable as an alternative to intrathecal alcohol or phenol for pain of malignant origin, especially in cases of pain in the upper parts of the body, cases where a large number of segments are involved, or where there is pain at several different levels. Clinical reports suggest that relief of pain can be achieved by irrigating with large volumes of weak hypertonic saline in the range of 600-1000 m.Osmols/ $\mathrm{Kg}(1.7-3 \%),{ }^{4}$ or by using smaller volumes of strongly hypertonic saline in the range of $2000-3000 \mathrm{~m}$.Osmols $/ \mathrm{Kg}(5.8-8.7 \%) .{ }^{3}$ The latter would appear to be the more desirable alternative, since the effects are concentrated over fewer segments, and any possible sequelae will be confined to a smaller area of spinal cord. Hitchock ${ }^{8}$ has recently reported improved results using small volumes of 10 per cent to 15 per cent solutions, but noted as well, an increase in morbidity.

From earliest history brine has been used for preserving food and for "pickling" meat. Prolonged marination in brine causes destruction of cells by osmotic 
dehydration. In the spinal canal solutions of brine are irritating, and presumably they damage surface layers, although to date no evidence exists of observable neurolysis in the spinal cord or roots. These solutions cause pain and when injected into the lumbar region result in sympathetic stimulation, manifested by hypertension or cardiac arrhythmias, ${ }^{2}$ local vasoconstriction with venous stasis and piloerection. ${ }^{2,4}$ In the clinical situation steps must be taken to relieve these undesirable irritative effects. General anaesthesia is commonly used, ${ }^{4,8}$ but it complicates an otherwise simple procedure, and prevents early observation of the neurological effects of the saline injection. Epidural analgesia has been used as an alternative technique for controlling side effects of intrathecal brine ${ }^{9}$ but this also makes the procedure more complicated, and the immediate area of segmental spread is masked by the independent effects of the epidural block.

Simplicity and ease of observation are retained by adding a weak concentration of local anaesthetic to the hypertonic saline. The local anaesthetic appears to perform three functions: it blocks conduction of pain from the irritated segments; it prevents a sympathetic discharge; and the level of skin analgesia indicates the segmental distribution of the solution. Also, since the patient is conscious, he can undergo the procedure in the sitting position when indicated for pain in the lower parts of the body.

In this series, injection of the hypertonic saline-local anaesthetic mixture was entirely painless and free of cardiovascular and other undesirable side effects. Comfort lasted for the duration of action of the 0.4 per cent lidocaine component, a period that varied between 50 and 90 minutes. Some aching pain in the lower back and limbs began in 6 instances as the local anaesthetic regressed, and this lasted for one or two hours. This pain was severe at first, but was readily controlled by a single dose of a narcotic. The observations of cerebrospinal fluid osmolality in Figure 1 demonstrate that severely dehydrating levels of hypertonicity were achieved and were maintained for at least 15 minutes.

Measurements of osmolality and chloride content required $2 \mathrm{ml}$ samples of cerebrospinal fluid, the first being taken 2 minutes after the injection. Since mixing does not take place evenly throughout the spinal fluid as shown by the limited segmental spread of anaesthesia the sampling process may be expected to dilute the hypertonic bolus, and the observed concentrations in the 5, 8, 10 and 15 minute samples are lower than would be expected were losses not incurred by sampling. Nevertheless, Stovall King and his colleagues have shown that persistent C-fibre blockade occurs after 15 minutes of exposure to brine in this range of osmolality. ${ }^{10}$ These authors have suggested that the chloride ion concentration is the important component in subarachnoid brine therapy. Figure 1 shows that the curves for cerebrospinal fluid osmolality and chloride content follow one another closely.

The results have not impressed us that intrathecal hypertonic saline is very effective for the prolonged relief of intractable pain in our hands; perhaps the addition of local anaesthetic in some way reduces the efficacy of the procedure. In this series, and in all our other cases of intrathecal hypertonic saline, injections have had to be repeated or succeeded by other techniques, such as alcohol, phenol in glycerine, or by cordotomy. However, although intrathecal brine did not usually 
produce more than moderate relief at any one session, it did little harm, and no sphincter disturbances arose from the procedure. Thus, the technique is an appealing option for trial in cases where bladder function is still unimpaired, and when pain involves a wide segmental distribution. Hitchcock's findings with 10 per cent to 15 per cent saline suggest that the margin between efficacy and paralysis is narrow, and qualitatively is little different from the same therapeutic dilemma encountered with intrathecal alcohol or phenol.

Lumbar and cisternal injection of hypertonic saline with or without local anaesthetic, in six dogs demonstrated obvious differences in the clinical states produced. Hypertonic saline without lidocaine caused irregular gasping respirations with a forced expiratory phase and visible muscle cramps. Muscle spasms were limited to the segmental area of stimulation; that is, the abdominal and leg muscles after lumbar injections and the tongue, jaw, neck and shoulder muscles after cisternal injection. One dog stopped breathing due to spasm of the respiratory muscles after intracisternal injection.

When the analgesic mixture of saline and 0.4 per cent lidocaine was injected, cramps were not seen, and the patterns of respiration, arterial blood pressure and cerebrospinal fluid pressure were much less affected. Only one dog developed apnoea, lasting 12 minutes, after the cisternal injection of 4 millilitres of the brinelidocaine mixture.

Absence of respiratory impairment in the three patients in whom skin analgesia developed as high as the second cervical dermatome, is explained on the basis of "differential spinal block," with preservation of motor function. However, the fact that no circulatory impairment such as hypotension or bradycardia occurred, even in the sitting position, is more difficult to explain.

Hypertension occurring as the local anaesthetic wears off is interesting. It may be a delayed response due to the cerebrospinal fluid being still sufficiently hyperosmolar to induce a nervous discharge. This would also explain the occasional occurrence of temporary cramping pain. Another possibility is the occurrence of intrathecal hypertension due to osmotic attraction of fluid into the subarachnoid space. The volume of the injected fluid would have to increase nine times, from 15 to 135 millilitres to reduce its osmolality to normal. However, if this were the cause, why does hypertension not occur more frequently? This problem is worthy of further study. It is interesting that no patient complained of headache despite arterial and probably cerebrospinal fluid hypertension. There were no cases of "spinal" headache.

An interesting question concerning the latency of lidocaine is raised by this study. The injection of a local anaesthetic alone into the cerebrospinal fluid, even in the usual concentrations, does not produce instantaneous anaesthesia; but the injection of hypertonic saline produces immediate pain. When the two are combined, however, no pain occurs; the patient merely describes a warm numb feeling spreading over the perineal region and legs. Does the hyperosmolarity enhance the onset of action of a weak lidocaine solution?

While the long-term results of subarachnoid injection of hypertonic saline remain to be determined, it is clear that the immediate effects of injection in the lumbar region are considerably ameliorated by the addition of a weak concentra- 
tion of local anaesthetic. Longer acting agents such as tetracaine, nupercaine or bupivacaine may have advantages over lidocaine in preventing delayed hypertension and pain. The procedure is immensely simplified by addition of lidocaine to the hypertonic saline and may become practical for trial in appropriate cases by practitioners in outlying, less specialized centres.

\section{ADDENDUM}

Since this paper was written, one further patient has been treated twice for pain in the perineum, right buttock and lower limb, associated with recurrent rectal carcinoma. He had already received a left percutaneous cervical cordotomy, with a sensory level at T11 on the right side.

Details of his cerebrospinal fluid osmolalities and chlorides are included in Figure 1 and they agree with the other data, except for a rapid fall following the first injection. There are several other interesting features:

1. The first treatment with the hypertonic saline-local anaesthetic mixture was relatively painful, though the patient was able to tolerate it without sedation or general anaesthesia. No rise in blood pressure or obvious fasciculation occurred.

2. No sensory level was achieved with the first injection (i.e., no spinal anaesthesia developed) even though free cerebrospinal fluid flow was obtained before and for 15 minutes after the injection, which proceeded as expected in every other way.

3. No relief of pain occurred in spite of high osmolalities being achieved in the cerebrospinal fluid ( $2440 \mathrm{~m}$. Osmols $/ \mathrm{Kg}$ ). This level fell more rapidly than the average.

4. The second injection, 3 days later, was painless and achieved sensory levels to C5 on the right and C8 on the left. No hypotension or respiratory impairment occurred, though mild buttock pain, requiring a single injection of an opiate, was associated with the termination of the local anaesthetic effect. There was no hypertension at any time. This second injection resulted in almost complete relief of pain which so far has lasted 5 weeks. It is interesting that the osmolalities achieved in the cerebrospinal fluid with this injection (1330 m.Osmols $/ \mathrm{Kg}$ ) were less than with the first. The solution of saline and lidocaine used at each injection was from the same batch.

5. This patient had abnormal cerebrospinal fluid proteins, the control prior to the first injection being $114 \mathrm{mg} \%$ and prior to the second injection $176 \mathrm{mg} \%$. His myelogram and bony $x$-rays were normal.

6. So far no adequate explanation for these findings has occurred to us, but it perhaps reinforces the value of attempting this procedure, possibly on several occasions, before using more complicated or dangerous techniques.

\section{SUMMARY}

Hypertonic saline, when injected into the lumbar subarachnoid space for the relief of intractable pain, causes pain, unpleasant muscle cramps and potentially 
dangerous sympathetic discharge. These side effects can be avoided by adding a weak concentration of local anaesthetic to the brine solution. Fourteen intrathecal injections of 8 per cent sodium chloride and 0.4 per cent lidocaine (osmolality : $2788 \mathrm{~m}$. Osmols $/ \mathrm{Kg}$ ) were made in 9 patients. Serial measurements of cerebrospinal fluid osmolality and chloride content were made during the succeeding 15 minutes. Cerebrospinal fluid osmolality increased four to eight-fold shortly after injection, and was still three to six times higher than normal 15 minutes later. The procedure was painless, and free of cardiovascular disturbances.

\section{RÉSUMÉ}

Lorsqu’injecté dans l'espace sous-arachnoidien lombaire pour le soulagement de la douleur incoercible, le sérum salé hypertonique occasionne de la douleur, des crampes musculaires désagréables et des impulsions sympathiques virtuellement dangereuses. Ces effets secondaires peuvent être évités en ajoutant à la solution salée une faible concentration d'anesthésique local. Quatorze injections intrathécales de chlorure de sodium à 8 pour cent et de lidocaine à 0.4 pour cent (osmolalité: $2788 \mathrm{mOsmols} / \mathrm{Kg}$ ) furent faites chez 9 malades. Des mesures en série de l'osmolalité du liquide céphalo-rachidien et de son contenu en chlorure furent faites au cours des 15 minutes subséquentes. L'osmolalité du liquide céphalorachidien augmenta de quatre à huit fois peu de temps après l'injection, et s'avérait encore de trois à six fois au-delà de la normale 15 minutes plus tard. Ce procédé se montra indolore et dénué de perturbations cardio-vasculaires.

\section{ACKNOWLEDGMENTS}

This work was supported in part by the Medical Research Council of Canada (Grant MA. 1008).

\section{REFERENCES}

1. Hrтснсоск, E. Hypothermic subarachnoid irrigation for intractable pain. Lancet $i$ : 11331135 (1967).

2. McKean, M. \& HITchсоck, E. Electrocardiographic changes after intrathecal hypertonic saline solution. Lancet $i i$ : 1083-1084 (1968).

3. Hrтснсоск, E. Osmolytic neurolysis for intractable facial pain. Lancet $i$ : $434-436$ (1969).

4. Colins, J.R., Juras, P.E., Van Houten, R.J., \& Spinell, L. Intrathecal cold saline solution: a new approach to pain (evaluation). Anesth. \& Analg. 48: 816-823 (1969).

5. O'Huggins, J.W., Padfield, A., \& Clapp, H. Possible complication of hypothermic saline subarachoid injection. Lancet $i: 567$ (1970).

6. Hттснсоск, E.R. Hypothermic saline subarachnoid injection. Lancet $i$ : 843 (1970).

7. Thompson, G.E. Pulmonary edema complicating intrathecal hypertonic saline injection for intractable pain. Anesthesiology 35: 425-427 (1971).

8. Hrtchсоcк, E. \& Prandini, M.N. Hypertonic saline in management of intractable pain. Lancet $i: 310-312$ (1973).

9. NeILSEN, J.S. A case of severe vascular insufficiency of the lower extremities treated by subarachnoid osmotic neurolysis. Canad. Anaesth. Soc. J. 18: 687-690 (1971).

10. King, J.S., Jewitr, D.L., \& Sundrerg, H.R. Differential blockade of cat dorsal root C fibres by various chloride solutions. J. Neurosurg. 36: $569-583$ (1972).

11. Lloyd, J.W., Hughes, J.T., \& Davies-Jones, G.A.B. Relief of severe intractable pain by barbotage of cerebro-spinal fluid. Lancet $i: 354-355$ (1972). 